\title{
DEGRADATION OF BIODEGRADABLE SINGLE-USE PLATES AND WASTE BAGS IN TERRESTRIAL AND MARINE ENVIRONMENTS
}

\author{
KAIRE TORN, GEORG MARTIN \& GRETA REISALU \\ Estonian Marine Institute, University of Tartu, Estonia
}

\begin{abstract}
Littering and microplastic are a rising problem in both the terrestrial and marine environment. The degradation of macrolitter into smaller particles is driven by several factors such as: material, temperature, UV light, grazers, etc. Field exposure experiments were conducted within the natural systems to assess how quickly fragmentation occurs under different environmental conditions. The degradation of disposable paper plates, biodegradable plates, and biodegradable waste bags was studied in two terrestrial (open-air vs. buried in soil) and two marine (submerged in seawater above sediment vs. buried in sediment) conditions. Additionally, both biodegradable items were labelled as compostable by the producer. Degradation under natural condition did not meet established official standards for the biodegradation. Products degradation rates were highest in the marine environment for sample products that were submerged in seawater but above the sediment, followed by those that were in the terrestrial environment and buried in the soil. The rate of degradation was affected by the prevalence of grazers in combination with wave action for the litter submerged in seawater but above the sediment. The biodegradable plates were completely degraded under these two conditions within 4 months. The loss of material was highest during the first months. Slowest degradation occurred in the open-air where the loss of all materials was only $8-17 \%$ after 10 months. Biodegradable plastic bags decomposed remarkably only in the seawater above the sediment, in other environments the loss of weight was less than $20 \%$ during the period of 10 months.
\end{abstract}

Keywords: discarded macrolitter, plastic pollution, biodegradable products, plastic deterioration, fragmentation, sea water, natural environment.

\section{INTRODUCTION}

Marine litter is recognized as a growing global problem. Although, plastic recycling is increasing, millions of tonnes of plastic still reach the marine environment each year. Plastics are of increasing concern due to their persistence and effects on the ocean's wildlife and potentially humans [1]. In the European Union, 80 to $85 \%$ of marine litter (measured as beach litter counts) is plastic, with single-use plastic items representing $50 \%$ of this [2]. Single-use plastic is a challenge to manage due to its lengthy degradation process and the production of fragmented residues. In this context, the use of biodegradable polymers presents itself as an alternative for reducing the long-term impact plastic materials have on the environment.

The global production and use of biobased and/or biodegradable plastics is on the rise [3]. Biodegradable or compostable plastics can be produced from either bio-based or fossil raw materials. Biodegradation is a complex phenomenon which occurs in multiple steps: abioticand biotic-deterioration, biofragmentation, and microbial assimilation and mineralization [4]. Biodegradable plastic is designed to breakdown once immersed in soil or fresh water. Compostable materials are designed for compostability in terrestrial landscapes, typically that of an industrial composting facility [5]. In less suitable conditions, they might biodegrade slowly or not at all or even fragment into microplastics [6], [7]. Within the natural environment, several conditions may increase the effect of mechanical degradation such as environmental factors like exposure to UV radiation and mechanical abrasion by wave action, and so forth [8]. 
The marine environment is not an optimal media for biodegradation as the necessary conditions for full degradation are not met (e.g. low temperature and oxygen level) [9]. At present, studies evaluating degradation of macrolitter in natural habitats [10], especially in marine environments are limited [11]. Degradation under laboratory conditions is different from degradation under natural conditions [12]. Laboratory tests are more suitable for assessing the stability of a material and do not take into account the influence of environmental factors. The aim of this study was to investigate the degradability of disposable plates and plastic bags in both the terrestrial and marine environment. The experiment was conducted in the natural environment to better examine the fragmentation of disposable items in different real-world conditions.

\section{MATERIAL AND METHODS}

\subsection{Materials}

Three widely used single-use products were selected for this study. Of these products, two types of plate (15 cm in diameter) were assessed. The first type of paper plate is one commonly used and composed of primarily of cellulose with a thin layer (less than $10 \%$ from product) of polyethene. The second type of plate selected is made of natural raw material and labelled as $100 \%$ biodegradable and compostable. The third item selected was a biodegradable waste bag with handles (61 volume) labelled as $100 \%$ biodegradable and compostable marked to conform with EN13432 standard. EN13432 requires compostable plastics to disintegrate after 12 weeks and completely biodegrade after six months under the conditions of industrial composting. As such $\geq 90 \%$ of the plastic material should have been converted to $\mathrm{CO}_{2}$ with the remaining share degraded into water and biomass.

\subsection{Experimental design}

To contain the sample products, bags were constructed of fiberglass mesh (mesh size $4 \times 4 \mathrm{~mm}$ ). The selected mesh size allowed for fauna to access the investigated products. Prior to the experiment the dry weight of each sample products was measured. The products under investigation were each placed into their own mesh bag and labelled before being closed by sewing. Triplicate samples for each three products were used to investigate each of the environmental conditions.

The degradation rate of the assessed products was tested in two terrestrial (open-air, buried in soil) and two marine (submerged in seawater above sediment, buried in sediment submerged by seawater) environments. Sample bags were anchored in place for each of their associated environmental conditions. The buried samples were covered with a 5-10 cm thick layer of soil or sediment.

The samples were removed from the experimental sites 2, 3, 4, and 10 months after installation. The samples were packed separately and transported into lab for further analysis. The material was removed from the bag, cleaned gently and carefully from extras (soil, sediment, roots) and dried at room temperature to constant weight. Weight loss was used to quantify the extent of degradation. Results were expressed as the percentage of remained dry weight of material compared to initial weight.

\subsection{Experimental location and conditions}

In situ degradation experiment was carried out in June 2018-April 2019 in Saaremaa island, Estonia. Terrestrial setup was performed in mowed lawn in Kõiguste $\left(58.3733^{\circ} \mathrm{N}\right.$, 
$22.9818^{\circ} \mathrm{E}$ ) where humus rich garden soil prevails. Field experiments in marine conditions were conducted in shallow, semi-enclosed Kõiguste Bay, northern Gulf of Riga, NE Baltic Sea $\left(58.3714^{\circ} \mathrm{N}, 22.9816^{\circ} \mathrm{E}\right)$. Bottom substrate of the location was fine sand with mud, water depth was $0.5 \mathrm{~m}$. The distance between terrestrial and marine experimental plot was $250 \mathrm{~m}$.

Experimental area lies in the northern part of the temperate climate zone, and in the transition zone between maritime and continental climate. Estonia has four seasons of nearequal length. For air temperature and sunshine hours nearest State Weather Service station (Roomassaare) was used. Water temperature was measured with a General Oceanics thermologger in Kõiguste Bay experimental site (Table 1). Ice coverage (thickness 5-15 cm) were registered in Kõiguste Bay (State Weather Service) in winter 2018-2019. During the experiment, the salinity of the bay was 5.5-5.8 PSU.

Table 1: Range of monthly average of temperatures and sunshine hours from June 2018 to April 2019. Recorded maximum of temperature is given in brackets.

\begin{tabular}{lccc}
\hline Season & $\begin{array}{c}\text { Air temperature } \\
\left({ }^{\circ} \mathrm{C}\right)\end{array}$ & $\begin{array}{c}\text { Water temperature } \\
\left({ }^{\circ} \mathrm{C}\right)\end{array}$ & Sunshine hours \\
\hline Summer & $15.2-20.3(30.3)$ & $15.9-23(30.5)$ & $286-377$ \\
Autumn & $4.8-14.7(22.5)$ & $10.3-15.5(21.5)$ & $28-204$ \\
Winter & $-1.9-0.9(7)$ & NA & $14-90$ \\
Spring & $1.6-6.7(22.5)$ & NA & $135-319$ \\
\hline
\end{tabular}

\subsection{Statistical analysis}

The results of the field experiments were statistically analysed using the factorial ANOVA: tree type of litter items, duration of experiment, four different environmental conditions and their combinations as the independent variables, and loss of weight as the dependent variable. Effects were considered to be statistically significant at $p<0.05$. Statistical analysis carried out in STATISTICA 10.

\section{RESULTS}

The experiment lasted for a period of 300 days beginning in the summer and concluding in the following spring. In general, the observed degradation was faster during the first months. We detected the decomposition of some of the sample products after as little as 3 months. The average degradation curves are plotted in Fig. 1.

The results of the experiment show that a products degradation rate varies as a factor of both its material composition and the environment in which it is immersed (Table 2, Fig. 2). Across the entirety of the experiment the change of mass was observed to be greatest when a product was submerged in seawater but above sediment, followed by that of being buried in soil. Submerged material was found to be completely or near totally fragmented after four months. Slowest degradation rate observed was in the open-air environment where the loss of all material was minor during the first 4 months, and only $8-17 \%$ by the conclusion of the experiment.

The weight loss of the biodegradable bags was significantly different from the plates and was found to be low (7-20\% loss) in all environments except when above marine sediment ( $86 \%$ loss). The degradation of both paper and biodegradable plates was similar, except when plates were buried in soil. 

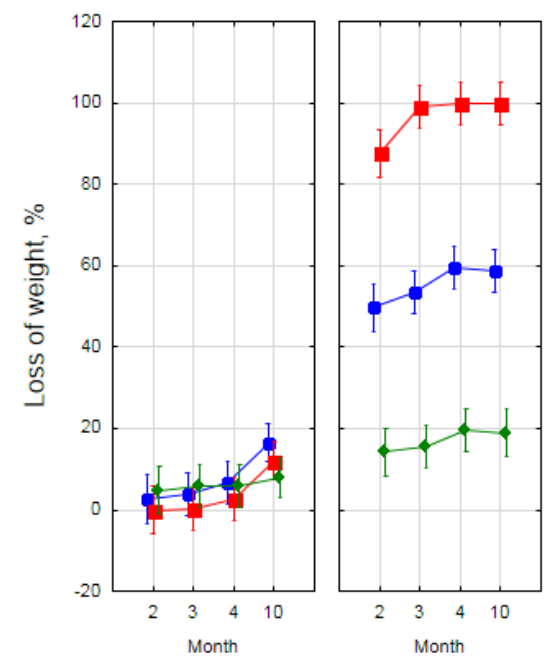

Open-air (terrestrial)
Buried in soil (terrestrial)

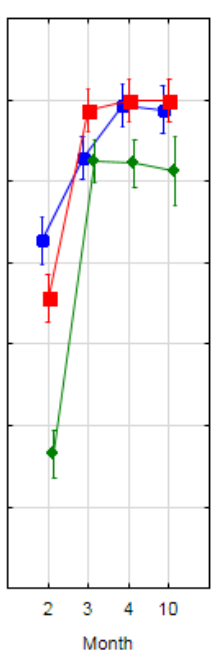

Above sediment (marine)

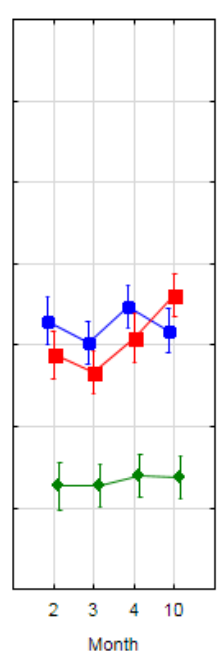

Buried in sediment (marine)
Paper plate

Biodegradable plate

Biodegradable bag

Figure 1: Weight loss (mean \pm 0.95 confidence interval, $n=3$ ) of selected products in different environmental conditions.

Table 2: Results of factorial ANOVA for product material, duration and environment on the degradation of sample products. All effects are significant $(p<0.05)$.

\begin{tabular}{|l|c|c|c|c|c|}
\hline & SS & Df & MS & $F$ & $p$ \\
\hline Intercept & 400,457 & 1 & 400,457 & $9,481.106$ & 0.0000 \\
\hline Material & 42,885 & 2 & 21,443 & 507.666 & 0.0000 \\
\hline Duration & 9,490 & 3 & 3,163 & 74.895 & 0.0000 \\
\hline Environment & 161,311 & 3 & 53,770 & $1,273.052$ & 0.0000 \\
\hline Material*Duration & 1,610 & 6 & 268 & 6.353 & 0.0000 \\
\hline Material*Environment & 36,779 & 6 & 6,130 & 145.129 & 0.0000 \\
\hline Duration*Environment & 14,759 & 9 & 1,640 & 38.827 & 0.0000 \\
\hline Material*Duration*Environment & 3,530 & 18 & 196 & 4.643 & 0.0000 \\
\hline
\end{tabular}

The biggest difference in the degradation rates for all of the measured products was when products were buried in the ground compared to when they were exposed in the open-air. If buried in the soil, biodegradable plates were completely fragmented after 3 months. In contrast, $41 \%$ of the paper plates and $11 \%$ of the biodegradable bags were remained at the end of experiment. Based upon visual estimations the biodegradable bags seemed usable with no fragmentation after a period of 10 months for the conditions of open-air and buried in sediment under seawater. 


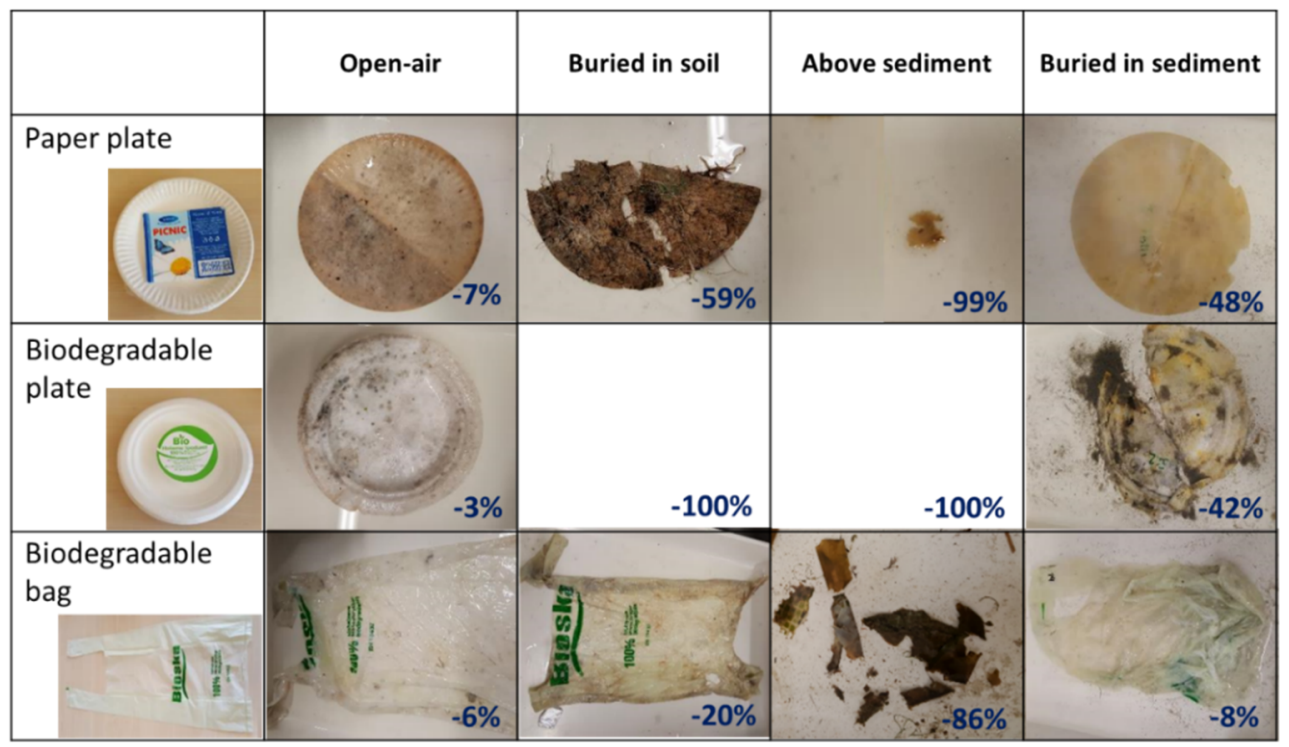

Figure 2: Examples of products after a 4 month degradation period. Average proportion of weight loss is shown numerically.

\section{DISCUSSION}

The present study provides insight into the potential behaviour of paper plates, biodegradable plates, and biodegradable bags under different terrestrial and marine conditions over a period of 300 days. The results of the experiment showed that degradation rates varied as a consequence of a products material composition and the environment it is immersed in. In general, degradation was faster during the first few months.

The rate of biodegradation is dependent on the concentration of enzymes, microorganisms, temperature, $\mathrm{pH}$ value, humidity, oxygen supply, and light [6]. All these factors vary in different environments. In marine conditions, mechanical effects due to wave action are added. However, the impact of grazing invertebrates cannot be underestimated. Based on visual observations, items were inhabited by amphipods (Gammaridae, Corophidae) and isopods (Idoteidae) during sampling. Similar findings are reported by previous whereby numerous grazing crustaceans have been involved in the degradation of plastic items within the marine environment [13], [14].

Compost incubation is generally considered the most efficient method for biodegradation [15]. However, a great number of single-use products are released into the natural environment instead of being composted. Based on our results, degradation rates were highest in the marine environment for sample products that were submerged in seawater but above the sediment. It has been noted previously that plastics buried in marine environment take a long time for degradation to occur [16]. In the context of this study, the lowest rate of degradation was observed in open-air conditions for all four of the studied environments. Contrary to that of previous studies, the non-degradable plastic fragmented in open-air faster when compared to the marine environment [7], [17]. However, in these previous studies the impact of grazers was limited as the sampled products were shielded by dense mesh. Furthermore, by positioning samples higher in the water column and further from the 
sediment, the consequence was reduced degradation through impact by macrobenthos grazing. Additionally, the effect of UV-light and wave activity may have been greater in the present study due to shallow depth of the experimental site.

Different plastics display different characteristics depending upon their chemical composition. Surprisingly, the degradation of the biodegradable bags was remarkably low compared to the other materials investigated. The only environment where these bags lost more than $80 \%$ of their material when submerged in seawater above the sediment. The material of the bag directly relates to its decomposition rate as demonstrated by a previous experiment investigating compostable plastic bags which observed total decomposition in seawater within 3-5 months [11]. In contrast, biodegradable plates buried in the soil and in the sea above the sediment displayed the greatest loss of material, decomposing completely within 3-4 months. Additionally, standard paper plates displayed a higher rate of degradation when compared to the biodegradable bags.

Currently, there are a limited number of products capable of biodegradation under natural conditions or compostable by a typical household. Biodegradation tests that meet the European Union standards are performed under idealized conditions that can only be achieved by industrial biodegradation or composting operations. For example, when testing the compostability of a product, the temperature is kept constant at $58^{\circ} \mathrm{C}$ with humidity and aeration controlled at optimal levels [18]. In regard to biodegradation standards in seawater, water temperature is based upon a $30^{\circ} \mathrm{C}$ setting. In the northern seas, including the experimental area of the Baltic Sea, temperatures in coastal areas during summer typically reach $20-22^{\circ} \mathrm{C}$ with occurring $30^{\circ} \mathrm{C}$ under atypical weather conditions and only in shallow bays. Thus, it is generally not possible to meet these conditions for the degradation of biodegradable products in nature or at home. This likely results in confusion for consumers as the conditions of how the standards are set are not indicated on the packaging with the products claims of rapidly degrading in the environment most likely unachievable. Labels for disposable biodegradable products should include the information about the degradation condition as well as the material and additives used.

There is a common misconception that biodegradable plastics are safe and environmentally friendly because they are produced using natural materials. Several studies have expressed various concerns regarding biodegradable plastics. It is true that most biodegradable plastics are produced from materials of biological origin however the production process usually includes using different compounds including additives and plasticizers. It has been shown that in the European market $80 \%$ of bio-based and/or biodegradable plastic products contained more than 1,000 chemicals, with $67 \%$ of the products tested containing hazardous chemicals [19].

Member States of the European Union are required to ensure environmentally sound waste management to prevent and reduce marine litter from both sea and land sources. Therefore, in 2021 single-used plastic and oxo-degradable plastics will be banned in Europe. The objective of the European Strategy for Plastics is to ensure that all plastic packages in the Union market are re-usable or easily recycled [2]. The strategy of the European Commission focuses on recyclable plastics rather than biodegradable plastics. Biodegradable and/or compostable plastics require separate treatment through sorting of waste collection. There is also a risk that the use of biodegradable products may endorse littering behaviour.

\section{CONCLUSION}

The rate of a materials degradation in different environments will strongly depend upon the local conditions to which they are exposed. The degradation of biodegradable products under natural conditions do not meet the requirements for biodegradation defined by current EU 
standards. The observed degradation rates were highest in the marine environment for sample products that were submerged in seawater but above the sediment, followed by those that were in the terrestrial environment and buried in the soil. In marine conditions, the impact of wave action and grazing by invertebrates on the degradation of a material cannot be underestimated. The degradation rate in an open-air was negligible. Biodegradable items from comprised of different materials showed very different results under the same environmental conditions. Therefore, labels for disposable biodegradable products should include the information about the appropriate degradation conditions as well as the materials and additives used.

\section{ACKNOWLEDGEMENTS}

This work was supported by the European Regional Development Fund via the Mobilitas Pluss (MOBERA12) of the Estonian Research Council. We would like to thank Imbi Püss and Tiia Möller for help in fieldwork. The authors thank Jack R. Hall for his help in editing the manuscript.

\section{REFERENCES}

[1] Jambeck, J.R. et al., Plastic waste inputs from land into the ocean. Science, 347(6223), pp. 768-771, 2015. DOI: 10.1126/science.1260352.

[2] Directive (EU) 2019/904 of the European Parliament and of the Council of 5 June 2019 on the reduction of the impact of certain plastic products on the environment. Official Journal of the European Union, L155. https://eur-lex.europa.eu/legal-content/EN/ TXT/PDF/?uri=CELEX:32019L0904\&from=EN. Accessed on: 4 May 2021.

[3] Report - Bioplastics Market Data 2019, Global production capacities of bioplastics 2019-2024. European Bioplastics, nova-Institute. https://docs.europeanbioplastics.org/publications/market_data/Report_Bioplastics_Market_Data_2019.pdf. Accessed on: 4 May 2021.

[4] Lucas, N., Bienaime, C., Belloy, C., Queneudec, M., Silvestre, F. \& Nava-Saucedo, J.E., Polymer biodegradation: Mechanisms and estimation techniques - A review. Chemosphere, 73(4), pp. 429-442, 2008. DOI: 10.1016/j.chemosphere.2008.06.064.

[5] Biodegradable and compostable plastics - Challenges and opportunities. European Environment Agency, Briefing no. 09/2020. https://www.eea.europa.eu/publications/ biodegradable-and-compostable-plastics._Accessed on: 4 May 2021.

[6] Haider, T.P., Völker, C., Kramm, J., Landfester, K. \& Wurm, F.R., Plastics of the future? The impact of biodegradable polymers on the environment and on society. Angewandte Chemie International Edition, 58(1), pp. 50-62, 2019.

DOI: 10.1002/anie.201805766.

[7] Napper, I.E. \& Thompson, R.C., Environmental deterioration of biodegradable, oxobiodegradable, compostable, and conventional plastic carrier bags in the sea, soil, and open-air over a 3-year period. Environmental Science and Technology, 53(9), pp. 4775-4783, 2019. DOI: 10.1021/acs.est.8b06984.

[8] Kershaw, P.J., Biodegradable Plastics and Marine Litter. Misconceptions, Concerns and Impacts on Marine Environments. United Nations Environment Programme (UNEP): Nairobi, 2015.

[9] Nazareth, M., Marques, M.R., Leite, M.C. \& Castro, Í.B., Commercial plastics claiming biodegradable status: Is this also accurate for marine environments? Journal of Hazardous Materials, 366, pp. 714-722, 2019. 
[10] Green, D.S., Boots, B., Blockley, D.J., Rocha, C. \& Thompson, R., Impacts of discarded plastic bags on marine assemblages and ecosystem functioning. Environmental Science and Technology, 49(9), pp. 5380-5389, 2015.

[11] O'Brine, T. \& Thompson, R.C., Degradation of plastic carrier bags in the marine environment. Marine Pollution Bulletin, 60(12), pp. 2279-2283, 2010. DOI: 10.1016/j.marpolbul.2010.08.005.

[12] Rutkowska, M. et al., Biodegradation of modified poly (E-caprolactone) in different environments. Polish Journal of Environmental Studies, 11(4), pp. 413-420, 2002.

[13] Welden, N.A. \& Cowie, P.R., Degradation of common polymer ropes in a sublittoral marine environment. Marine Pollution Bulletin, 118(1-2), pp. 248-253, 2017.

[14] Hodgson, D.J., Bréchon, A.L. \& Thompson, R.C., Ingestion and fragmentation of plastic carrier bags by the amphipod Orchestia gammarellus: Effects of plastic type and fouling load. Marine Pollution Bulletin, 127, pp. 154-159, 2018.

[15] Roy, P.K., Hakkarainen, M., Varma, I.K. \& Albertsson, A.C., Degradable polyethylene: Fantasy or reality. Environmental Science and Technology, 45(10), pp. 4217-4227, 2011.

[16] Kumar, A.G., Anjana, K., Hinduja, M., Sujitha, K. \& Dharani, G., Review on plastic wastes in marine environment - Biodegradation and biotechnological solutions. Marine Pollution Bulletin, 150, p. 110733, 2020.

[17] Biber, N.F., Foggo, A. \& Thompson, R.C., Characterising the deterioration of different plastics in air and seawater. Marine Pollution Bulletin, 141, pp. 595-602, 2019.

[18] Innocenti, F.D., Biodegradability and compostability. Biodegradable Polymers and Plastics, eds. E. Chiellini \& R. Solaro, Springer: Boston, MA, pp. 33-45, 2003. DOI: 10.1007/978-1-4419-9240-6_2.

[19] Zimmermann, L., Dombrowski, A., Völker, C. \& Wagner, M., Are bioplastics and plant-based materials safer than conventional plastics? In vitro toxicity and chemical composition. Environment International, 145, p. 106066, 2020.

DOI: 10.1016/j.envint.2020.106066. 